\title{
COTA DE SOLIDARIEDADE: COMPARANDO POLÍTICAS ENTRE CIDADES NORTE AMERICANAS E SÃO PAULO
}

\section{INCLUSIONARY ZONING: COMPARING POLICIES FROM UNITED STATES CITIES AND SÃO PAULO}

\section{Ana Beatriz Pahor Pereira da Costa 1}

Universidade de São Paulo, Faculdade de Arquitetura e Urbanismo, São Paulo, SP, Brasil, ana.pahor.costa@usp.br

Giovanna Helena Benedetti de Albuquerque ${ }^{2}$

Universidade de São Paulo, Faculdade de Arquitetura e Urbanismo, São Paulo, SP, Brasil, giovanna.albuquerque@usp.br

Luiz Filipe Rampazio ${ }^{3}$

Universidade de São Paulo, Faculdade de Arquitetura e Urbanismo, São Paulo, SP, Brasil, luiz.rampazio@usp.br

\section{Resumo}

O seguinte artigo expõe como se deu a implementação do instrumento de Cota de Solidariedade tanto nas cidades dos Estados Unidos da América quanto em São Paulo. Por meio deste artigo procura-se demonstrar as diferenças e similaridades entre os programas de Inclusionary Zoning americanos, vigentes desde a década de 1970, e a recente aplicação do instrumento da Cota de Solidariedade em São Paulo por meio do Plano Diretor da cidade aprovado em Julho de 2014. Buscou-se também entender os sucessos e falhas das estratégias, e as características que tornaram algumas experiências mais eficazes do que outras, através de analises do histórico americano de enfrentamento da questão, de estudos sobre determinados planos de algumas cidades americanas e da elaboração da lei paulistana. Entendendo o quadro urbano brasileiro como um cenário antagônico, em que a efetividade dos instrumentos urbanísticos muitas vezes fica subordinada aos interesses da sociedade de elite, o artigo busca uma análise crítica e construtiva da incorporação da Cota de Solidariedade ao novo Plano Diretor, através das experiências estudadas, das repercussões da lei, da avaliação das posições tomadas na implantação desse instrumento e seus possíveis sucessos e falhas na aplicação paulistana, cujos resultados serão concretos nos anos que virão.

Palavras-chave: Cota de solidariedade. Habitação social. Plano diretor.

\begin{abstract}
The following article exposes how the implementation of the Inclusionary Zoning took place both in cities of the United States of America and São Paulo. By this article hopes to demonstrate the differences and the similarities between the american inclusionary zoning programs, active since the 1970s', and the recent implementation of the Cota de Solidariedade tool in São Pauloin the city's master plan approved on July 31, 2014. There was also an effort put into understanding the success and the failures of strategies and the characteristics that made some programs more successful than others, through the analysis of amercian historical of facing the matter, studies about programs of a few american cities and about São Paulo's law. Understanding that the efficiency of urbanistic tools is mostly subordinated to the interest of specific groups in the brazilian antagonic urban scenario, this article aims for a critical and constructive analysis of the incorporation of the Cota de Solidariedade into the city's master plan, by studiying the decisions made in the implementation of this tool and it's likely sucesses and failures in São Paulo's application, with results to be seen in the next few years.
\end{abstract}

Keywords: Inclusionary zoning. Affordable housing. Master planning.

How to cite this article:

COSTA, Ana Beatriz Pahor Pereira da.; ALBUQUERQUE, Giovanna Helena Benedetti de; RAMPAZIO, Luiz Filipe. Cota de Solidariedade: Comparando políticas entre cidades norte americanas e São Paulo. PARC Pesquisa em Arquitetura e Construção, Campinas, v. 6, n. 1, p. 56-68, jan./mar. 2015 


\section{Introdução}

Para o urbanismo contemporâneo, a construção de habitação para as camadas mais pobres em regiões afastadas e desprovidas de infraestrutura é a principal causa de muitos problemas urbanos e da desigualdade social.

No Brasil, programas de produção habitacional de baixa renda adotados até hoje não representaram mudanças efetivas do ponto de vista da inclusão social, por relegarem essas moradias às áreas pobres e periféricas (LABCIDADE, 2014). Somado a isso, tradicionalmente a política habitacional brasileira baseia-se na oferta de subsídios e créditos individualizados para a compra de propriedade privada; porém as necessidades habitacionais da população de baixíssima renda não são atendidas desse modo. O resultado disso é mostrado nas grandes cidades brasileiras: o adensamento nas favelas e periferias e a sobreoferta de unidades habitacionais para a demanda de renda média que permanecem "encalhadas", "engrossando" o número de casas e apartamentos vazios, que hoje já é quase igual ao déficit habitacional do país (ROLNIK; NAKANO, 2009).

Adotada em muitas cidades, principalmente nos EUA, a Cota de Solidariedade é, no Brasil, um instrumento urbanístico que busca unir a produção de habitação de mercado à produção de habitação social, apresentandose como uma ferramenta de diversificação social e criando vizinhanças mais plurais.

Enquanto aqui a Cota se trata de um instrumento urbanístico legal e obrigatório aplicado pelo município, nos EUA o Inclusionary Zoning se caracteriza como um programa definido pelos condados (counties), com caráter mandatório ou facultativo que obriga ou sugere sua aplicação nas municipalidades.

Essa ferramenta legal cria a possibilidade ou demanda que construtoras de empreendimentos residenciais separem uma determinada quantidade de unidades habitacionais construídas para habitação social, a serem vendidas para famílias de baixa renda. Além de aumentar a oferta de habitação de baixo custo, esse instrumento permite a criação de residências acessíveis em regiões de crescimento imobiliário.

A cota solidária auxilia as administrações públicas a melhorar o acesso de moradores e trabalhadores de baixa renda às regiões mais estruturadas. Entre outros benefícios, essa medida facilita a contratação e manutenção de empregados em escritórios e empresas, pela maior proximidade ao local de trabalho e facilidade de acesso à rede de transporte local; evita o surgimento de bairros homogêneos e fechados; permite o acesso dos mais pobres às infraestruturas urbanas e gera diversidade social, aumentando a segurança e a qualidade de vida dos moradores.

Esse instrumento se apresenta vantajoso por ser passível de aplicação em diferentes condições de mercado. Em comunidades sofrendo gentrificação a cota solidária é capaz de diminuir a saída de moradores de baixa renda e sua consequente mudança para áreas periféricas; já em novos bairros ou áreas em crescimento populacional ou construtivo as unidades de cota solidária criam residências de baixo custo e previnem a geração de comunidades homogêneas, fechadas ou excluídas.

A adoção do instrumento de cota solidária engloba muitas variáveis. Não há um modelo pronto desse instrumento urbanístico, e sim uma grande quantidade de opções a serem vistas separadamente e então avaliadas em conjunto para entender seus impactos sobre o adensamento, o mercado imobiliário e a inclusão social na cidade.

O primeiro passo é identificar e entender os problemas e necessidades da cidade. Os pontos mais importantes são o déficit habitacional no território, a localização e o número de indivíduos a serem beneficiados pelo programa e a análise dos aspectos urbanos da região, considerando a situação atual e as prováveis mudanças provenientes da aplicação de uma medida como essa. Identificados esses pontos, devem ser traçados objetivos para seu uso, para assim adequá-los aos parâmetros específicos da legislação. Os objetivos costumam ter diretrizes abrangentes, baseadas nos problemas levantados ao se estudar as condições urbanas e traçam a finalidade da adoção do instrumento.

Algumas cidades, como Boulder, no Colorado (EUA) estabelecem a aplicação desse instrumento para empreendimentos a partir de um determinado tamanho ou número de unidades. Por exemplo:

\section{Any development on a site larger than 10 acres or containing 50 or more $d w e l l i n g$ units shall include at least twenty percent of the total number of dwelling units within the development as permanent affordable units. (BOULDER, 2015)}

Projetos que atingem ou excedem as dimensões definidas na legislação devem incluir unidades de baixo custo. A determinação da aplicação, tanto a partir do tamanho em área construída quanto em número de unidades habitacionais, visa atingir todos os tipos de edifícios residenciais. Por exemplo, edifícios de alto padrão e baixa densidade, onde as unidades possuem grandes áreas, são submetidos pela metragem construída; já condomínios com apartamentos menores e muitas unidades são submetidos pelo número de habitações que comportam. 
Essa medida não se resume necessariamente a novos empreendimentos, podendo ser aplicada também em projetos de reabilitação de edifícios ou construção de anexos; intervenções como essas podem vir a alcançar o tamanho ou número de unidades definido para a aplicação da cota solidária.

A quantidade de unidades de cota solidária por empreendimento costuma ser dada em porcentagens, e varia conforme a necessidade de prover habitação social. Essa porcentagem pode ser dividida entre as faixas de renda atendidas pelo programa, definindo valores maiores ou menores de acordo com a quantidade de famílias necessitadas em cada uma.

A diferenciação nas fachadas e elementos visuais de empreendimentos de baixa renda, uma das características responsáveis por distanciar imóveis de mercado e habitação social e gerar maior discriminação e segregação, é abordada em muitos programas, como no programa de Burlington, EUA:

Affordable inclusionary units may differ from the market units in a Covered Project with regard to interior amenities and gross floor area, provided that:

(i) these differences, excluding differences related to size differentials, are not apparent in the general exterior appearance of the Project's units; and

(ii) these differences do not include insulation, windows, heating systems, and other improvements related to the energy efficiency of the Project's units;

(iii) the gross floor area of the affordable inclusionary units is not less than minimum requirements established by the City. (BURLINGTON, 2014)

A exigência é de que as unidades habitacionais de baixa renda sejam visualmente compatíveis com empreendimentos de mercado, sem distinção entre as fachadas das mesmas. Para tornar possível a diminuição do custo de produção da habitação, com o objetivo de não gerar prejuízos para quem executa a obra, é permitido utilizar materiais de menor custo no interior das unidades, desde que estes não causem desconforto ou diminuam a eficiência energética; diminuições na área total das unidades também são permitidas, desde que estejam iguais ou acima da metragem mínima exigida pela administração local.

Para evitar o não cumprimento da construção das unidades de habitação social, muitos programas exigem que a construção das unidades de mercados e da porcentagem acessível seja realizada ao mesmo tempo, apresentando à administração local um cronograma contendo o planejamento das construções e provando sua simultaneidade.

Apesar de parecer rígida, a grande maioria das legislações de cota solidária permite uma alternativa à construção das unidades habitacionais no mesmo edifício ou empreendimento (SCHUETZ; METZER; BEEN, 2008). As exigências ou opções variam conforme a flexibilidade dos programas e a necessidade de construir habitação social. As alternativas costumam incluir o pagamento de taxas, construção em outro terreno, doação de terras, ou a execução de outra obra de infraestrutura que possa trazer benefícios para a comunidade.

Legislações mais rígidas permitem recorrer a essas alternativas caso seja provado que a opção escolhida poderá ser mais benéfica ou que a construção de unidades dentro do empreendimento poderá resultar em complicações ou prejuízos que a tornem pouco interessante do ponto de vista da inclusão social e urbana.

As alternativas costumam ter suas próprias especificações e exigências. Algumas exigem a doação de uma quantia no valor correspondente a uma dada porcentagem do valor do terreno original. Outras permitem a construção em outro terreno, desde que seja feito um número maior de unidades de habitação social.

Apesar do controle proposto, em muitos casos o pagamento de taxas acaba por ser muito menos custoso do que a produção das unidades (SCHUETZ; METZER; BEEN, 2008), o que apesar de contribuir em parte com a produção de habitação - pois o dinheiro recebido é direcionado para a produção de moradias de baixa renda em outro tipo de programa - pode acabar por falhar nas missões principais do instrumento, como o acesso democrático ao direito à cidade e o equilíbrio social e econômico em comunidades urbanas.

Nos Estados Unidos, as unidades de baixo custo são comercializadas às famílias de baixa renda após um processo de seleção feito pelo empreendedor. Os parâmetros para ser estar dentro da faixa autorizada a comprar essas unidades são definidos nas legislações de Cota de Solidariedade. Parte das unidades produzidas pode ser vendida à municipalidade ou ONGs para serem comercializadas posteriormente.

Uma vez que uma parte dos apartamentos vendidos passa a proporcionar menor retorno de capital por ser vendido a baixo custo, caso não houvesse uma compensação para essa perda de lucro a política se tornaria desinteressante ou desvantajosa para os empreendedores. Tendo em vista o ponto negativo desse instrumento para os agentes do mercado, as 
legislações oferecem maneiras de minimizar as perdas sofridas (CALAVITA; GRIMES; MALLACH, 1997), isentando-os de certas obrigações como obras de infraestrutura, estacionamentos e exigências quanto aos materiais usados na construção. Outra maneira de realizar essa compensação é oferecendo um bônus de densidade, ou seja, dando aos empreendedores o direito de construir maior área do que permite o zoneamento local, podendo assim construir mais unidades comuns para serem comercializadas no mercado imobiliário tradicional.

Para garantir a manutenção do baixo custo das habitações, torna-se necessário estabelecer limites e controle também para as revendas, ou seja, para aquelas vendas realizadas pelos primeiros compradores. $\mathrm{O}$ aumento no preço das unidades deve se resumir ao ajuste devido ao aumento da inflação no período transcorrido desde a compra anterior e em alguns casos, aos gastos e às melhorias feitas na unidade, este último critério sendo dotado de restrições para não extrapolar a faixa de preço acessível às famílias de baixa renda.

A Cota de Solidariedade é um instrumento formado pela junção de muitas variáveis que determinam sua abrangência, maleabilidade, e influências sobre a construção no território urbano. Para que essa política seja efetiva, é preciso levar em consideração todos os aspectos e consequências de cada uma das definições adotadas. Sua obrigatoriedade, rigidez quanto à localização das unidades de caráter social, aparência, público ser atendido, alternativas à construção podem definir o sucesso ou fracasso da política, que depende inteiramente $\mathrm{da}$ vontade $\mathrm{da}$ municipalidade de incentivar a inclusão social através da construção de habitações populares em áreas dotadas de infraestrutura.

\section{A aplicação em cidades americanas}

Concebidos na década de 1960, os programas de cota solidária passaram a ser implementados a partir da década de 1970 pelos governos estaduais dos Estados Unidos. Sua criação e adoção ocorreram a partir de dois importantes fatores: os altos custos da habitação em estados como a Califórnia e também como resposta às práticas excludentes, entrando em consonância com movimentos pelos direitos civis. $\mathrm{Na}$ época, governos como o de Nova Jersey utilizavam-se das leis de zoneamento de maneira a privilegiar as elites, que usufruíam de habitação de qualidade nas áreas privilegiadas das cidades, ao passo que excluía minorias, principalmente raciais, e classes mais pobres destas áreas (CALAVITA, 2006), sem garantir-lhes habitação minimamente adequada.
Sua implementação nas cidades norte-americanas buscou tratar de novas formas o problema da habitação. Essas formas lutavam contra o modelo de exclusão vigente em diversas municipalidades do país, de maneira a promover maior integração socioeconômica das comunidades.

Algumas medidas políticas foram importantes para impulsionar o desenvolvimento dos programas de cota de solidariedade, começando pela criação do Departament of Housing and Urban Developement $H U D$ (Departamento de Habitação e Desenvolvimento Urbano), em 1965, e em 1968 a aprovação pelo Congresso norte-americano do Housing Act, que destinava recursos federais para a construção de habitação para a população de baixa renda. Nesse mesmo ano foi aprovado o Civil Rights Act (Declaração dos Direitos Civis), coibindo qualquer agente do mercado imobiliário de agir de forma discriminatória, baseado em cor, crença ou nacionalidade. O Housing and Community Developement Act (Lei de Habitação e Desenvolvimento Comunitário) de 1974 endossa a lei anterior de 1968, incluindo a integração socioeconômica na política federal dos Estados Unidos (CALAVITA, 2006). Apesar da implementação das leis e dos esforços comunitários, estes não foram muito bem-sucedidos, mas acabaram abrindo caminho para um novo pensamento sobre a inclusão e habitação no país.

Nesse mesmo período, a questão ambiental esboçou-se como uma nova preocupação, que passou ficar em voga, começando a questionar a máxima de que o crescimento das cidades é bom e inevitável.

Alguns anos mais tarde, no início da década de 1980, durante o mandato do presidente Ronald Regan (19811989), o governo norte-americano passou por um período de desregulamentação, fazendo com que as verbas federais destinadas à criação de habitações fossem cortadas, delegando essa função aos estados da federação. Assim, as medidas para criação de habitação social através de programas de cota de solidariedade tomaram força.

Esse breve resumo busca traçar uma linha do tempo sobre como se deu a construção em âmbito nacional de políticas que levaram à implementação dos programas de cota de solidariedade, para assim iniciar-se a análise de alguns casos implementados e seus desdobramentos.

Um dos primeiros programas a ser desenvolvido e implantado foi o Moderately Priced Dwelling Unit Program em Montgomery County, no estado de Maryland. A partir de 1973, revelou-se como um dos mais importantes e duradores programas do país tendo produzido mais de 10 mil unidades de habitação social num período de 25 anos (CALAVITA, 2006). Vale 
ressaltar, entretanto, que este programa teve alcance local, não fazendo parte de uma política articulada do estado de Maryland. No âmbito de poder estadual, dois outros estados irão se destacar por seus programas de cota solidária: Califórnia e Nova Jersey.

No que diz respeito ao estado da Califórnia, deve-se entender que o abrangente uso dos programas de cota de solidariedade surgiu como uma resposta à crise da construção de habitações, a partir da década de 1970, que se estendeu pelas décadas seguintes. Esses programas foram mais intensamente usados na década de 1990, até o início dos anos 2000, sendo que entre 1994 e 2003, o número de cidades que adotaram a cota solidária no estado passou de 64 para 107. Vale pontuar, que ao longo de 30 anos, cerca de 34 mil unidades de habitação acessíveis foram produzidas no âmbito do programa no estado da Califórnia.

David Rosen, um dos fundadores da DRA - David Paul Rosen \& Associates - uma firma de consultoria responsável pelo desenvolvimento e estudo de políticas de Cota de Solidariedade, chegou à conclusão de que a Cota "is not associated with a negative effect on housing production. In fact, in most jurisdictions as diverse as San Diego, Carlsbad and Sacramento, the reverse is true. Housing production increased, sometimes dramatically, after passage of inclusionary housing ordinances" (apud CALAVITA,2006, p.6).

Em Nova Jersey, a implementação dos programas teve início em 1975, quando a Suprema Corte do Estado declarou que a lei de zoneamento, até então, havia sido utilizada de maneira inconstitucional, posto que excludente. A partir de então, todos os municípios do estado deveriam promover a partilha de terras de forma justa, garantindo o acesso de população de baixa renda à habitação.

Tais políticas não se restringiram a esses dois estados, mas foram neles que, de maneira muito semelhante, os governos estaduais tiveram grande influência nas decisões dos municípios no que tange ao acesso à habitação. Outros estados também implantaram medidas nesse sentido, mas não foram em todos que elas conseguiram ser plenamente implementadas, podendo ser entendidas apenas como aplicações pontuais. A exemplo, do estado de Massachusetts, onde, segundo Ziegler, a lei de zoneamento de 1975 foi bem-sucedida, logrando aumentar a construção de habitação social, mas, efetivamente, não garantiu a criação de áreas com integração socioeconômica (apud. CALAVITA, 2006, p.4), conforme proposto pelos programas de cota solidária.

Debruçando-se novamente sobre aplicações mais locais, de forma a entender a política dos instrumentos e a construção de seus programas, tem-se o exemplo da cidade de Boulder, no Colorado, onde o programa de Cota Solidária foi utilizado como uma das formas de atingir a meta de produção de habitação social estabelecida no Plano Diretor. Um dos objetivos tido como mais importante era a produção de habitação cuja faixa de preço seria acessível à população que constituía a força de trabalho na região; dessa forma dar-se-ia a essas pessoas a oportunidade de viver e trabalhar em locais próximos.

O programa proposto também ressaltava a maior integração social e o equilíbrio nas comunidades, provendo habitação para diferentes classes sociais. Um ponto a ser ressaltado nesses objetivos era a preocupação em assegurar que as unidades de cota solidária continuassem acessíveis às pessoas de muito baixa e baixa renda, pessoas com necessidades especiais e trabalhadores da cidade, mesmo após terem sido compradas pela primeira vez, ou seja, nos casos de revenda.

Por sua vez, a cidade de Sacramento, Califórnia, definiu como objetivo público alcançar uma população diversificada e equilibrada, com ofertas de moradias para todas as classes sociais. A convivência de indivíduos em condições econômicas diferenciadas abre espaço para uma ocupação dos bairros ambiental e socialmente mais saudável, além de segura e com maior qualidade de vida.

Segundo os dados levantados em seus estudos, a cidade passava por uma diminuição na oferta de casas com preços acessíveis para famílias de baixa renda, pois os novos empreendimentos não apresentavam oportunidades para esses indivíduos em decorrência do alto custo das unidades e do mercado imobiliário inflacionado. As famílias de baixa renda eram, consequentemente, excluídas de muitos bairros, criando locais de estratificação econômica e social, privando as camadas mais pobres do acesso direto ao sistema público de saúde, segurança, lazer e etc. Como solução para esses problemas, ao implantar o Plano Diretor da cidade foi implementada a medida que salientava a necessidade de aliar a criação de novos empreendimentos residenciais nas áreas em crescimento às habitações de interesse social. Nesse Plano ficou estabelecido também que caberia à cidade manter um quadro econômico regulado para essas moradias $\mathrm{e}$ incentivar o desenvolvimento dos empreendimentos, com o objetivo de futuramente criar vizinhanças mistas e atender as necessidades das classes mais baixas.

A quantidade de programas de Cota de Solidariedade criados e aplicados nos EUA é ampla e apresenta 
diferenças em cada local. A política pode ser obrigatória ou voluntária, definir tamanhos variados de empreendimentos para aplicação dos instrumentos, estabelecer diferentes porcentagens de unidades a serem destinadas à habitação social e pode ainda ser mais ou menos controladora em relação às medidas alternativas à construção de habitação de baixo custo. É possível ter uma noção mais detalhada dos programas de cada cidade ao analisar as respectivas políticas de zoneamento.

\section{A cota de solidariedade em São Paulo}

No Brasil, a ideia de se aplicar o "Inclusionary zoning" foi abordada de forma concreta, primeiramente, na elaboração do Plano Diretor Estratégico da cidade de São Paulo (Projeto de lei n ${ }^{\circ} 688 / 13$ ). As primeiras redações da seção do PDE que tratavam da Cota de Solidariedade, como foi chamado o "Inclusionary zoning”, possuíam uma abordagem simples e que não abria outras possibilidades para o seu cumprimento. $\mathrm{O}$ seu principal aspecto era a obrigatoriedade da cota de solidariedade de $10 \%$ da área construída computável do empreendimento, para aqueles maiores que $20.000 \mathrm{~m}$, para famílias com renda de até 6 salários mínimos. O site oficial do

PDE

(http://planodiretor.camara.sp.gov.br/wp/) disponibiliza algumas das revisões pelas quais passou o seu texto, sendo que por meio delas é possivel analisar as mudanças entre um e outro, até que se chegue à versão final aprovada em 31 de Julho.

Em ordem cronológica, a primeira versão disponível é o "Substitutivo da CPUMMA" aprovado em $1^{\text {a }}$ votação" aos 23/04/2014. Nessa versão os apectos gerais explicitados nos parágrafos acima se mantêm, abrindose ao produtor duas alternativas além da produção no próprio terreno; a primeira seria a produção de empreendimento de HIS, de área minima equivalente aos $10 \%$, porém, em outro terreno; e a segunda seria a doação de um terreno de área equivalente. As duas altervativas deveriam estar localizadas dentro da mesma macroárea do empreendimento original.

A versão seguinte é o " $1^{\circ}$ Substutivo Apresentado em Plenário", de 17/06/2014. Esta versão em muito difere da descrita acima. Enquanto os aspectos gerais se mantêm, as alternativas apresentadas nessa versão diferem, destacando-se a retirada da possibilidade de doação de terrenos, com permissão, em contrapartida, de depósito financeiro em montante equivalente ao valor de $10 \%$ dos metros quadrados do total da área construída computável do empreendimento original; outra modificação concerne à exigência para que o empreendimento de HIS produzido fora do do local empreendido seja dentro da Macrozona de Estruturação e Qualificação e não mais dentro da Macroárea do empreendimento.

Neste momento vale a explicação das diferenças entre Macrozona de Estruturação e Qualificação e as Macroáreas. O Plano Diretor Estratégico de 2014 divide a cidade em apenas duas Macrozonas: A Macrozona de Proteção e Recuperação Ambiental e a Macrozona de Estruturação e Qualificação Urbana, sendo a primeira caracterizada por terrotórios ambientalmente frágeis, presença de manaciais e biodiversidade que demandam cuidados especiais, e a segunda abrange praticamente toda a área urbanizada do município. As Macrozonas são subdivididas em áreas menores, as chamadas Macroáreas pelo PDE, como podemos observar nas Figuras 1 e 2 nas próximas páginas.

Dessa forma, ao modificar a redação da lei - de macroárea para macrozona - cria-se a oportunidade para o empreendedor de construir o empreendimento de HIS em praticamente qualquer região da área urbanizada da cidade, e não apenas na região com carateristicas de urbanidade similares ao empreendimento original, perdendo-se assim o caráter integrador social do instrumento.

Nesta versão também aparece uma nova condição a ser atendida: "\$ $5^{\circ}$ - A obrigação estabelecida no caput se estende aos empreendimentos com área construída computável inferior a $20.000 \mathrm{~m}$ (vinte mil metros quadrados), quando: a) originários de desmembramentos aprovados após a publicação desta lei, com área computável equivalente superior a 20.000 $m$ " (Substitutivo $\mathrm{n}^{\circ} 02$ ao Projeto de Lei 688/2013, Câmara Municipal de São Paulo).

$\mathrm{O} 2^{\circ}$ e $3^{\circ}$ Substitutivos apresentados em Plenário são da mesma data e, no que diz respeito à cota de solidariedade, apresentam redação igual à do Substitutivo da CPUMMA. Embora a redação dos últimos Substitutivos se assemelhassem mais ao primeiro texto, a versão final da lei possui uma redação muito próxima à do $1^{\circ}$ Substitutivo.

A versão oficial da legislação sobre a Cota de Solidariedade (Lei $\mathrm{n}^{\circ} 16.050$ de 31 de Julho de 2014, Art.111), integrante do PDE, estabelece como exigência para a obtenção do certificado de conclusão de empreendimentos de grande porte, a inclusão de planos e de projetos urbanísticos, embora nada seja dito no PDE sobre a qualidade urbanística e arquitetônica desses projetos de HIS. Vale a ressalva de que a Cota de Solidariedade terá legislação própria a ser apresentada em 12 meses após a oficialização do plano em 31 de Julho de 2014, a legislação própria poderá sanar algumas dessas questões. 
Nesta versão, ficou estabelecido que a cota de solidariedade de ser aplicada adicionalmente às possíveis áreas da gleba já demarcadas como HIS. A taxa de $10 \%$ vale para as quatros alternativas apresentadas na lei, e expostas a baixo.

No caput da versão final da lei lê-se:

"Art. 111. Fica estabelecida como exigência para o certificado de conclusão de empreendimentos imobiliários de grande porte ou implantação de planos e projetos urbanísticos a Cota de Solidariedade, que consiste na produção de Habitação de Interesse Social pelo próprio promotor, doação de terrenos para produção de HIS ou a doação de recursos ao Município para fins de produção de Habitação de Interesse Social e equipamentos públicos sociais complementares à moradia."

As quatro opções de cumprimento da lei da cota de solidariedade citadas no "caput" são melhor explicadas no art. $112, \S 2^{\circ}$ :

$\S \quad 2^{\circ} \quad$ Alternativamente ao cumprimento da exigência estabelecida no "caput" deste artigo, o empreendedor poderá:

I - produzir Empreendimento de Habitação de Interesse Social com no mínimo a mesma área construída exigida no "caput" desse artigo em outro terreno, desde que situado na Macrozona de Estruturação e Qualificação Urbana, excluída a Macroárea de Redução da Vulnerabilidade Urbana e os Setores Jacu-Pêssego, Arco Leste, Noroeste e Fernão Dias da Macroárea de Estruturação Metropolitana;

II - doar terreno de valor equivalente a $10 \%$ (dez por cento) do valor da área total do terreno do empreendimento, calculado conforme Cadastro de Valor de Terreno para fins de Outorga Onerosa, situado na Macrozona de Estruturação e Qualificação Urbana, excluída a Macroárea de Redução da Vulnerabilidade Urbana e os Setores JacuPêssego, Arco Leste, Noroeste e Fernão Dias da Macroárea de Estruturação Metropolitana;

III - depositar no Fundo de Desenvolvimento Urbano - FUNDURB, em sua conta segregada para Habitação de Interesse Social, 10\% (dez por cento) do valor da área total do terreno calculado conforme
Cadastro de Valor de Terreno para fins de Outorga Onerosa, destinado à aquisição de terreno ou subsídio para produção de HIS, preferencialmente em ZEIS 3. (2014, p. 7, Subseção IX, Art. 111

Essas quatro maneiras de se cumprir a exigência da lei produção de Habitação de Interesse Social pelo produtor do empreendimento no próprio lote; doação de terrenos para a produção de Habitação de Interesse Social (HIS); produção de Habitação de Interesse Social em outro terreno; doação de recursos ao Município por meio de uma conta destinada à produção de Habitação de Interesse Social ou equipamentos públicos complementares à moradia - acabam por apresentar uma grande discrepância em relação ao valor apresentado no "caput" de 10\%. Em alguns momentos, produção no próprio terreno ou produção em outro terreno, os $10 \%$ se referem ao total de área construída computável do empreendimento original, nos casos da doação de terreno ou doação de recursos financeiros, os $10 \%$ referem-se ao valor da área do terreno do empreendimento original calculado com base no Cadastro de Valor de Terreno para fins de Outorga Onerosa. Essas diferenças entre os valores atribuídos aos $10 \%$ tornam algumas alternativas mais financeiramente interessantes para os incorporadores responsáveis pelos empreendimentos com área construída computável acima de $20.000 \mathrm{~m}$.

Outro aspecto importante da legislação vigente é que os $10 \%$ destinados à Cota de Solidariedade entram como um adicional ao coeficiente de aproveitamento estabelecido para aquela região. Ou seja, adicionam-se $10 \%$ de área construída computável ao que já estava previsto, os quais deverão ser destinados à Cota de Solidariedade. Assim, num terreno de $20.000 \mathrm{~m}$ e coeficiente de aproveitamento 1, que se enquadra nas exigências para a Cota de Solidariedade, poder-se-á construir $22.000 \mathrm{~m}$, dos quais $2.000 \mathrm{~m}$ se destinarão a Habitação de Interesse Social. Esse aumento de 10\%, no entanto, como podemos ver no artigo $112, \S 2^{\circ}$, III do PDE deverá ser "destinado à aquisição de terreno ou subsídio pra produção de HIS, preferencialmente em ZEIS 3." (SÃO PAULO. Lei n 16.050 de 31 de Julho de 2014, 2014) por meio do FUNDURB (Fundo de Desenvolvimento Urbano.

Os produtores que optarem por adquirir outro terreno de área equivalente, ao invés de construir a Habitação de Interesse Social no próprio terreno do empreendimento, podem adquiri-lo em qualquer lugar da Macrozona de Estruturação e Qualificação Urbana, excluída a Macroárea de Redução da Vulnerabilidade Urbana e os Setores Jacu-Pêssego, Arco Leste, Noroeste e Fernão Dias da Macroárea de Estruturação 
Metropolitana (SÃO PAULO (Cidade). Lei n ${ }^{\circ} 16.050$ de

31 de Julho de 2014, 2014).

Figura 1. Macrozonas da cidade de São Paulo conforme determinado pelo Plano Diretor Estratégico.

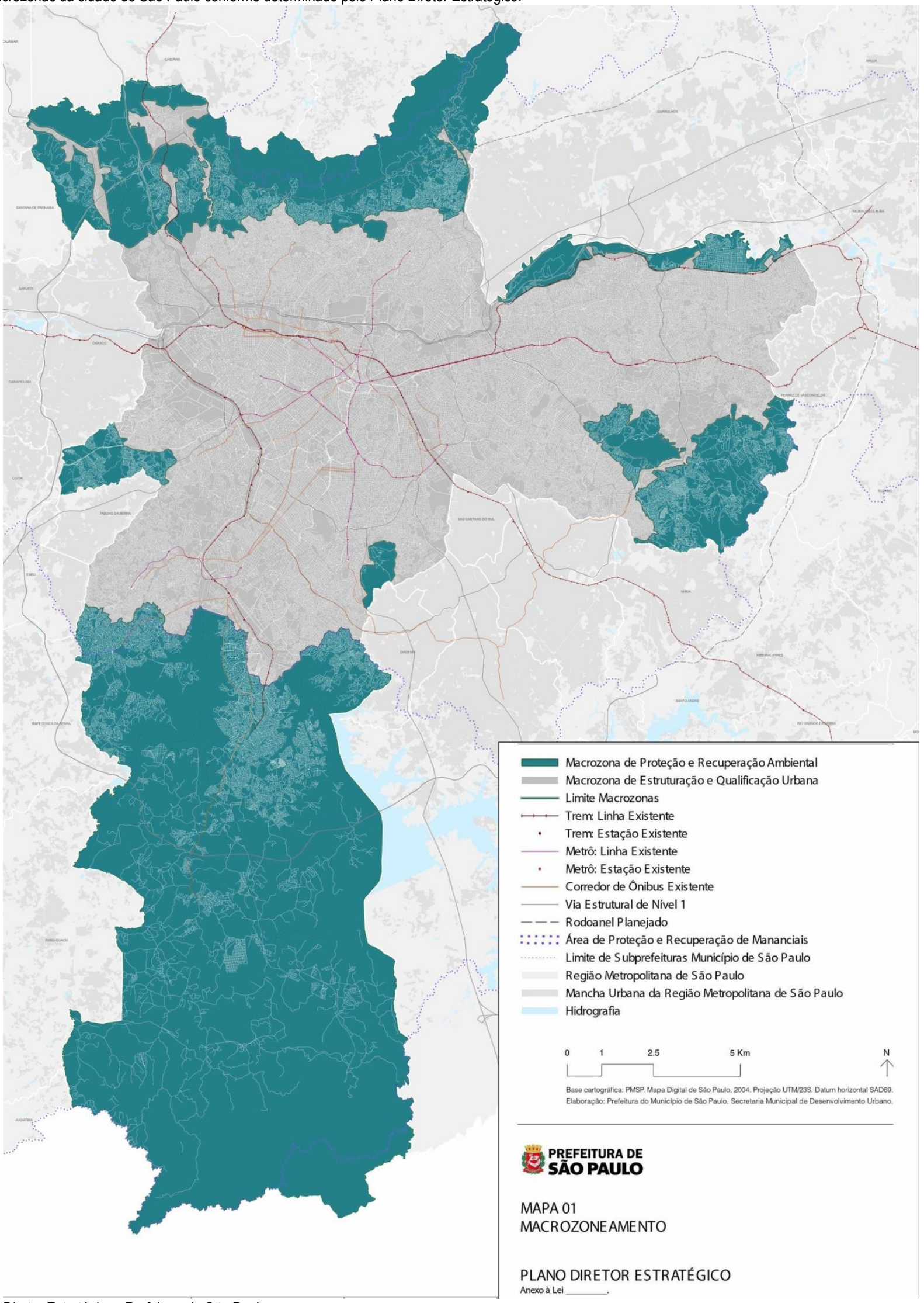


Figura 2. Macro áreas da cidade de São Paulo conforme determinado pelo Plano Diretor Estratégico.

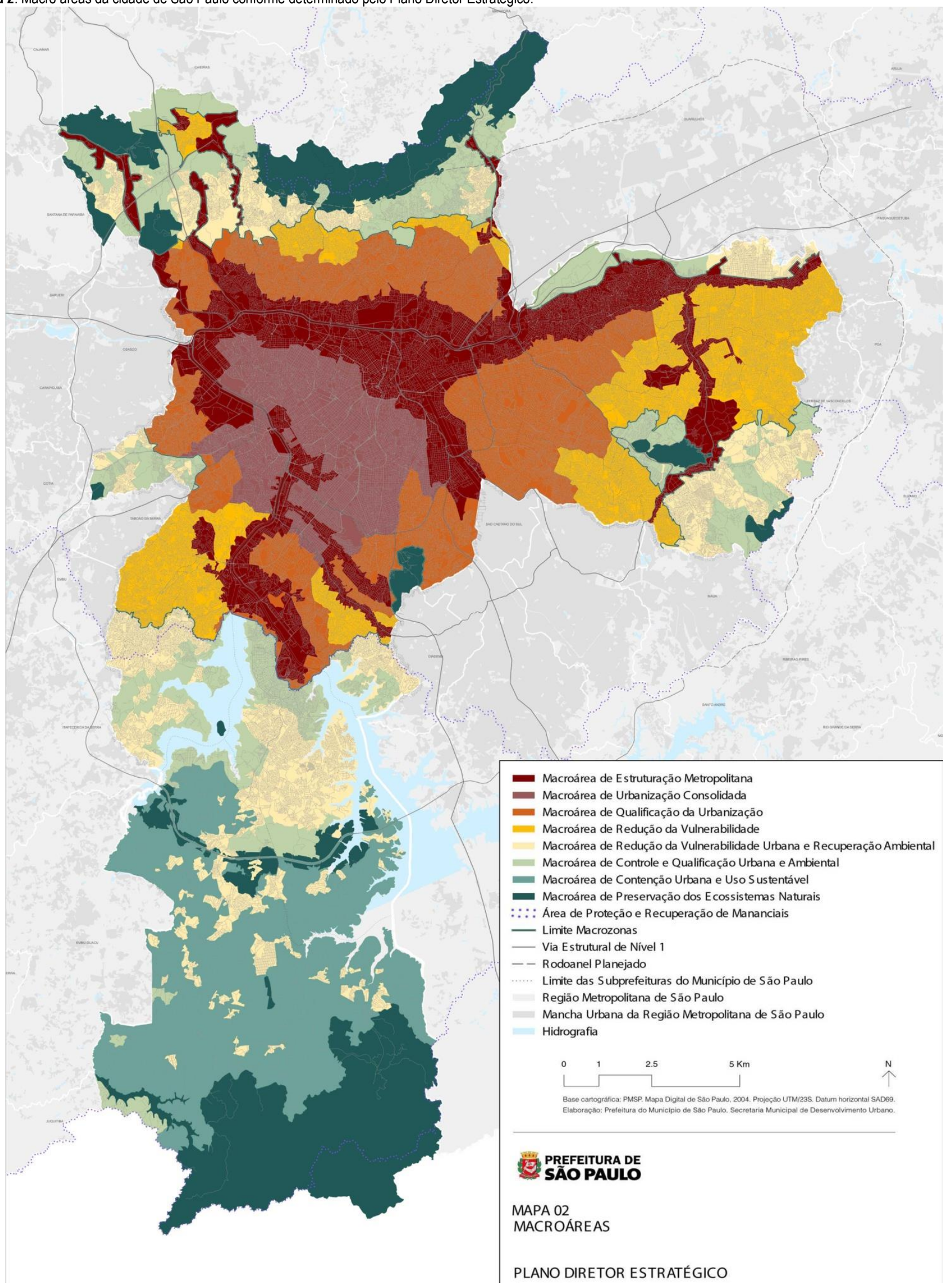

Fonte: Plano Diretor Estratégico - Prefeitura de São Paulo. 


\section{Repercussões da lei}

Após a aprovação do PDE, o urbanista João Sette Whitaker publicou um texto, em 29 de Novembro de 2014, intitulado "O patrimonialismo e as leis facultativas: o caso da cota de solidariedade em São Paulo" no qual discorre sobre o que considera os pontos problemáticos da lei e também seu aspecto "facultativo".

O termo "facultativo" é por ele empregado para explicar essas leis cuja redação dá margem a flexibilização da sua execução, como no caso da cota de solidariedade tal como foi aprovada. O objetivo principal, qual seja a produção de Habitação de Interesse Social no mesmo terreno de grandes empreendimentos, torna-se apenas uma das opções apresentadas ao produtor, fazendo com que a lei "não seja efetivamente cumprida" (Whitaker, 2014). Esse aspecto é apontado pelo autor não apenas como um caso isolado, mas como um evento generalizado. Em suas palavras:

"A lei, no Brasil, é um tanto quanto maleável, e isso é um dos reflexos mais claros do que se denomina de Estado e sociedade patrimonialistas, em que o público não é bem público, e a máquina "pública" mais serve, na verdade, para manter as hegemonias dominantes.".

A crítica de Whitaker à lei continua destacando as consequências que essa facultatividade gera nesse caso específico. Segundo ele, a construção dessas Habitações de Interesse Social no mesmo terreno do empreendimento ou em área próxima ajuda a aproximar a população de seus empregos e assim reduzir a chamada pendularidade. Essa redução, no entanto, deixaria de existir com a possibilidade do produtor construir essas habitações em qualquer local da Macrozona de Estruturação e Qualificação. Ao possibilitar a implantação dessas HIS em uma área tão ampla, a lei acaba possibilitando que as construtoras procurem por terrenos mais baratos - como forma de reduzir os custos da obra - que costumeiramente se encontram nas regiões mais periféricas da cidade.

As alterações feitas na legislação da cota de solidariedade ao longo do processo de desenvolvimento do Plano Diretor Estratégico, podem ter sido uma reação à pressão do setor imobiliário atuante na capital temerosos dos custos que a implementação da cota poderia acarretar. Temor esse perceptível na fala de Tito Khzouz Sanchez de 31 de Outubro de 2013 "As consequências da cota de solidariedade podem inviabilizar o negócio para o empreendedor, já que parte do terreno não será utilizada para a comercialização e sim para o HIS, o que acarreta perda de VGV (valor geral de vendas)". (MARIANE, 2013)
Outro aspecto problemático da lei, segundo o mesmo autor, é o da possibilidade de se transferir uma quantia em dinheiro equivalente ao valor de $10 \%$ da área do empreendimento aos fundos da prefeitura voltados à Habitação Social. Isso modifica o objetivo da lei de oferecer terra à população, um bem de tão difícil acesso na cidade.

"Agora, a terra virou pó, ou melhor, dinheiro, para produzir casas provavelmente bem longe, como fazem costumeiramente as políticas habitacionais, o que aliás continua sendo praxe na atual gestão" (WHITAKER, 2014)

\section{Considerações finais}

As variações nos componentes da política, como a sua obrigatoriedade ou não, e ainda a porcentagem de unidades a serem separadas para produção de habitação social, têm impacto significante na quantidade de habitação de baixo custo produzida e em como o programa afeta a oferta e os preços das unidades de mercado (SCHUETZ; METZER; BEEN, 2008). Os estudos dos casos de aplicação da cota solidária se mostram de melhor entendimento e mais facilmente criticáveis ao serem analisados dentro de uma comparação regional entre os programas criados e seus resultados. Por fim, as inúmeras maneiras de aplicar a cota de solidariedade demonstram sua flexibilidade como instrumento urbanístico, sendo passível de adaptação segundo a localidade onde for aplicada. Os exemplos apresentados de cidades norte-americanas, que num cenário global são os melhores quanto à forma de aplicação e resultados obtidos, servem como balizadores para novas experiências e implementações, bem como servirão de parâmetro para avaliação das decisões tomadas em relação à cota solidária no Plano Diretor de São Paulo, sempre tendo em mente as realidades socioeconômicas de cada país em que foi adotada.

O tamanho estabelecido pela legislação da cidade de São Paulo, como mínimo a partir do qual os empreendimentos deverão incluir a cota solidária $20000 \mathrm{~m}^{2}$-, foi uma boa escolha, eis que abrange também empreendimentos de médio porte, e não somente empreendimentos de grande porte.

Contudo, a porcentagem de unidades destinadas à habitação social, $10 \%$ do total no texto da lei paulista, parece pouca e incipiente, se considerarmos o déficit habitacional da cidade e a forte segregação entre os bairros centrais e mais estruturados e as áreas periféricas. Essa porcentagem poderia ser revista, e possivelmente aumentada, dependendo do empreendimento. Em algumas cidades norte-americanas, cerca de um terço 
dos empreendimentos devem destinar de 11 a $15 \%$ das unidades a habitação acessível, podendo chegar, em alguns casos a $25 \%$ (SCHUETZ; METZER; BEEN, 2008).

Espera-se maior flexibilidade da lei no sentido que ela consiga abarcar o maior número possível de empreendimentos, gerando assim mais unidades de habitação acessível e maior quantidade de áreas socialmente diversificadas.

Nas cidades norte-americanas, apesar de ser da escolha do município a obrigatoriedade ou não dos programas, a grande maioria optou por impor a cota de solidariedade aos novos empreendimentos. Em São Paulo, a lei aprovada tem, teoricamente, caráter obrigatório, muito embora as alternativas por ela própria deixadas como um meio de contorná-la façam com que seu objetivo seja muito pouco incisivo.

A flexibilidade de um programa de Cota de Solidariedade deve estar ligada à oferta de opções, caso não seja vantajoso ou possível realizar a construção da habitação social no mesmo terreno. Na Califórnia, EUA, pelo menos $80 \%$ das cidades com programa de Cota de Solidariedade oferecem alternativas para a construção dentro do empreendimento (NHC, 2004). No programa previsto no PROJETO DE LEI N ${ }^{\circ} 688 / 2013$, Plano Diretor Estratégico (SÃO PAULO, 2013, p. 7), são oferecidas três opções alternativas à produção de habitação social no terreno do empreendimento, conforme já explicado acima.

Como visto, a primeira medida permite a produção de Habitação de Interesse Social (HIS) com no mínimo a mesma área, desde que situada na mesma Macrozona. Considerando as grandes dimensões das Macrozonas na cidade de São Paulo, torna-se questionável a flexibilidade decorrente dessa opção, uma vez que empreendedores, ao construírem em bairros de alto padrão, cuja metragem tem custo elevado, podem optar pela produção da mesma quantidade de unidades de HIS em uma área de vulnerabilidade situada dentro da Macrozona, o que na prática tem os mesmos efeitos da produção de habitação realizada até hoje no país. A construção de unidades em terrenos isolados ou fora da malha urbana limita os benefícios do programa, principalmente no que diz respeito à integração social.

Em alguns casos, é exigido que o empreendedor construa mais unidades habitacionais do que as exigidas para seu terreno, uma estratégia que tem como prioridade assegurar a produção de habitação e não necessariamente sua inserção urbana.

A segunda alternativa é a oferta de terras. Essa medida deve considerar a qualidade da terra doada, seu tamanho, formato, topografia e localização. A existência de infraestrutura adequada, limitações ambientais, disponibilidade de recursos para a construção de habitação no novo terreno são, entre outros, elementos indispensáveis a serem considerados quando da realização da oferta. Tendo-se em vista a futura regulamentação da lei específica, tais aspectos relacionados à qualidade do terreno doado poderão ser especificados. Ao oferecer essa alternativa à construção de habitação social, limita-se a eficiência do programa no âmbito da produção habitacional em áreas de melhor qualidade urbanística.

A terceira e última alternativa propõe a doação de $10 \%$ do valor total da área do terreno. O pagamento de taxas é um dos aspectos mais polêmicos das alternativas, podendo ser extremamente ineficaz, dependendo de seu método de cálculo e sua aplicação. Essa é a alternativa mais comum nos EUA, e costuma ser calculada em função da quantidade de unidades ou da área construída não realizada (NHC, 2004), diferentemente da legislação de São Paulo, que a determina somente em função do preço do terreno.

Apesar de serem comuns as alternativas nos programas americanos, o sucesso da Cota de Solidariedade depende também da atuação firme por parte das administrações no sentido de demonstrar que o uso de alternativas pode não ser tão vantajoso e trazer menos benefícios para a cidade. Em Washington, D.C., por exemplo, é permitido optar pelos outros meios caso seja provado que a construção no terreno pode acabar por ter custos extremamente elevados e inviabilizar sua oferta às populações de baixa renda sem causar grandes prejuízos ao empreendedor (SCHUETZ; METZER; BEEN, 2008). Cidades que optaram pelo uso de alternativas sob certas condições tiveram mais sucesso na produção de habitação do que as que não ofereceram nenhuma opção (NHC, 2004).

A ausência de uma legislação que determine parâmetros para a diferenciação nas fachadas e elementos visuais de empreendimentos de baixa renda é um ponto a ser criticado, já que essa característica contribui para a segregação e preconceito.

Os programas de cota solidária, tanto nos Estados Unidos como em São Paulo, apresentam-se, em sua teoria, como alternativas inovadoras para a questão da habitação social e do acesso igualitário à cidade. Partem da premissa de que é necessário construir uma sociedade mais heterogênea e diversa, uma cidade na qual as famílias não seriam expulsas de seus bairros devido ao processo de gentrificação, onde as pessoas poderiam morar perto de seus trabalhos e gastar menos 
tempo - e menos recursos - para locomover-se todos os dias.

Os mecanismos criados para se atingir tais objetivos são diversos. Nos EUA, o caráter Estadual das leis permite que várias soluções diferentes sejam adotadas, conforme demonstrado anteriormente, algumas mais restritivas, outras mais abrangentes. No Brasil, temos apenas o caso de São Paulo para análise, porém este parece abarcar todas as características abrangentes que as legislações americanas desenvolveram.

As diversas alternativas apresentadas, bem como sua falta de especificidade tornam a lei paulista aberta à interpretação do produtor. Não há especificações, como em alguns casos americanos, de que o exterior das habitações sociais seja semelhante aos das outras unidades, não há uma exigência de que essas habitações sejam construídas no próprio terreno, nem ao menos impõe a utilização de uma área próxima para isso. A possibilidade de um pagamento em dinheiro pelo produtor simplesmente o isenta da responsabilidade da produção social.

A legislação paulistana é inovadora pela sua própria existência, é uma grande conquista implementada no novo Plano Diretor, porém não se deve olhar para ela com olhos acríticos. Ao analisar os planos americanos percebe-se que existem maneiras melhores de se aplicar a cota solidária sem que sejam necessárias mudanças radicais no que já foi feito em São Paulo.

\section{Agradecimentos}

Os autores registram seus agradecimentos à FAUUSP, ao Professor Doutor Leandro Medrano do Departamento de História da Faculdade de Arquitetura e Urbanismo da USP e aos editores da revista PARC pelos comentários e críticas feitos ao artigo.

\section{Referências}

BOULDER. Boulder, Colorado-Municipal Code. Title 9 - Land Use Code, chapter 13/2015. This Code is enacted to protect and promote the health, safety, and general welfare of the present and future inhabitants of Boulder County and to guide future growth, development, and distribution of land uses within Boulder County. Disponível em:

$<$ http://www.bouldercounty.org/doc/landuse/landusecode.pdf >. Acesso em: 20 de abril de 2015.

BURLINGTON. Burlington Comprehensive Development Ordinance. Inclusionary and Replacement Housing, Article 9/2014. Explains the City's authority to enact zoning and other development bylaws, and describes the process by which these regulations are prepared and modified. Disponível em: $<$

http://www.burlingtonvt.gov/sites/default/files/PZ/CDO/20140718\%20ART09-Housing.pdf >. Acesso em: 20 de abril de 2015.

CALAVITA, N. Inclusionary Housing in the US and Europe. Istambul: 42nd ISoCaRP Congress, 2006.

CALAVITA, N.; GRIMES, K.; MALLACH, A. Inclusionary Housing in California and New Jersey: A Comparative Analysis. Housing Policy Debate, Washington D.C., v. 8, n. 1, p.109-142, 1997.

LABCIDADE - LABORATÓRIO ESPAÇO PÚBLICO E DIREITO À CIDADE. Ferramentas para avaliação da inserção urbana dos empreendimentos MCMV. São Paulo: FAUUSP, 2014. Disponível em: <http://www.labcidade.fau.usp.br/?page_id=224>. Acesso em: 15 de Mar. 2015

MARIANE, A. Cota de solidariedade aflige incorporadores e é aplaudida por urbanistas. Revista Construção Mercado, São Paulo, 11 de out. 2013. Disponível em: < http://construcaomercado.pini.com.br/negocios-incorporacao-construcao/noticias/cotade-solidariedade-aflige-incorporadores-e-e-aplaudida-por-urbanistas-300094-1.aspx > Acesso em: 15 de Mar. 2015

NHC - NATIONAL HOUSING CONFERENCE, Inclusionary Zoning: the California Experience. NHC Affordable Housing Policy Review, Washington D.C., v. 3, n. 1, 2004.

SÃO PAULO (Cidade). PROJETO DE LEI N 688/2013. Aprova a Política de Desenvolvimento Urbano e o Plano Diretor Estratégico do Município de São Paulo e revoga a Lei 13.430/2002. Disponível em: $<$ http://gestaourbana.prefeitura.sp.gov.br/arquivos/PDE-Suplemento-DOC/PDE SUPLEMENTO-DOC.pdf > Acesso em: 20 de abril de 2015. 
SÃO PAULO (Cidade). Substitutivo da CPUMMA aprovado em $1^{\mathrm{a}}$ votação. Dispõe sobre a Política de Desenvolvimento Urbano, o Sistema de Planejamento Urbano e o Plano Diretor Estratégico do Município de São Paulo. Disponível em:

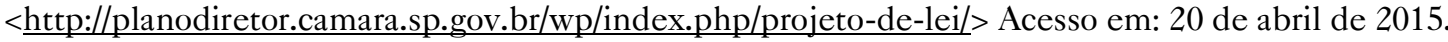

SÃO PAULO (Cidade). SUBSTITUTIVO N01 AO PROJETO DE LEI N 688/2013. Aprova a Política de Desenvolvimento Urbano e o Plano Diretor Estratégico do Município de São Paulo e revoga a Lei 13.430/2002. Disponível em: < http://planodiretor.camara.sp.gov.br/wp/index.php/projeto-de-lei/ > . Acesso em: 20 de abril de 2015.

SÃO PAULO (Gidade). SUBSTITUTIVO N02 AO PROJETO DE LEI No 688/2013. Aprova a Política de Desenvolvimento Urbano e o Plano Diretor Estratégico do Município de São Paulo e revoga a Lei 13.430/2002. Disponível em: < http://planodiretor.camara.sp.gov.br/wp/index.php/projeto-de-lei/ > . Acesso em: 20 de abril de 2015.

SÃO PAULO (Gidade). SUBSTITUTIVO Nº3 AO PROJETO DE LEI No 688/2013. Aprova a Política de Desenvolvimento Urbano e o Plano Diretor Estratégico do Município de São Paulo e revoga a Lei 13.430/2002. Disponível em: < http://planodiretor.camara.sp.gov.br/wp/index.php/projeto-de-lei/ > . Acesso em: 20 de abril de 2015.

SCHUETZ, J.; MELTZER, R.; BEEN, V. 31 Flavors of Inclusionary Zoning: Comparing policies from San Francisco, Washington, D.C. and Suburban Boston. 2008. 29 f. Working Paper. Furman Center for Real Estate and Urban Police. New York University, Nova York, 2008.

ROLNIK, R.; NAKANO, K. As armadilhas do pacote habitacional. Le Monde Diplomatique Brasil, São Paulo, mar. 2009. Disponível em: < http://www.unmp.org.br/index.php?option=com_docman\&task=doc_download\&gid=88\&Itemid=95 > Acesso em: 15 de Mar. 2015

WHITAKER, J. S. O patrimonialismo e as leis facultativas: o caso da cota de solidariedade em são Paulo. Cidade para que(m)?. São Paulo, 29 nov. 2014. Disponível em: $<$ http://cidadesparaquem.org/blog/2014/11/29/o-patrimonialismo-e-as-leisfacultativas-o-caso-da-cota-de-solidariedade-em-so-paulo > Acesso em: 02 fevereiro 2015.

\section{${ }^{1}$ Ana Beatriz Pahor Pereira da Costa}

Graduando de Arquitetura e Urbanismo. Endereço postal: Rua das Orquídeas, 780 , São Bernardo do Campo, SP. 09810-390

${ }^{2}$ Giovanna Helena Benedetti de Albuquerque

Graduando de Arquitetura e Urbanismo. Titulação máxima. Endereço postal: Av. Dionysia Alves Barreto, nº11, Osasco, SP. 06086-050

\section{${ }^{3}$ Luiz Filipe Rampazio}

Graduando de Arquitetura e Urbanismo. Titulação máxima. Endereço postal: Rua harmonia, 539, Sumarézinho, SP. 05435-902 